Article

\title{
Characterization of the Principal Constituents of Danning Tablets, a Chinese Formula Consisting of Seven Herbs, by an UPLC-DAD-MS/MS Approach
}

\author{
Changsen Zhan ${ }^{1,2,3,4}$, Aizhen Xiong ${ }^{1}$, Danping Shen ${ }^{2,4}$, Li Yang ${ }^{1, *}$ and Zhengtao Wang ${ }^{1,4, *}$ \\ 1 The MOE Key Laboratory for Standardization of Chinese Medicines and the SATCM Key Laboratory for \\ New Resources and Quality Evaluation of Chinese Medicines, Institute of Chinese Materia Medica, \\ Shanghai University of Traditional Chinese Medicine, Shanghai 201203, China; \\ zhanchangsen@shpl.com.cn (C.Z.); a.z.xiong@hotmail.com (A.X.) \\ 2 Shanghai Hutchison Pharmaceuticals Co., Ltd., Shanghai 200331, China; dpshen@shpl.com.cn \\ 3 Shanghai Engineering Research Center for Innovation of Solid Preparation of Traditional Chinese Medicine, \\ Shanghai 200331, China \\ 4 Shanghai R \& D Center for Standardization of Traditional Chinese Medicines, Shanghai 201203, China \\ * Correspondence: yl7@shutcm.edu.cn (L.Y.); ztwang@shutcm.edu.cn (Z.W.); \\ Tel: +86-21-5132-2506 (L.Y.); +86-21-5132-2506 (Z.W.); Fax: +86-21-5132-2519 (L.Y. \& Z.W.)
}

Academic Editor: Derek J. McPhee

Received: 6 April 2016; Accepted: 11 May 2016; Published: 14 May 2016

\begin{abstract}
Danning Tablets are a traditional Chinese formula showing broad clinical applications in hepatobiliary diseases and containing a diversity of bioactive chemicals. However, the chemical profiling of the formula, which serves as the material foundation of its efficacy, is really a big challenge as Danning Tablets consist of seven herbs from different origins. An ultra-performance liquid chromatography coupled to diode array detection and electrospray ionization mass spectrometry (UPLC-DAD-ESI-MS/MS) approach was developed to characterize the principal polyphenol constituents in the formula. As a result, a total of 32 constituents, including 14 anthraquinones and their glucosides, four anthrones, two naphthalene glycosides, two stilbenes and 10 flavonoids were identified based on their retention time, UV absorption and MS/MS fragmentation patterns. The sources of these compounds were also illustrated. Most of the bioactive anthraquinone derivatives were found in Rhei Radix et Rhizoma or Polygoni Cuspidati Rhizoma et Radix, which are the Emperor drugs in the formula for its clinic usage. These findings indicate the merit of using this integrated UPLC-DAD-ESI-MS/MS approach to rapidly illustrate the chemical foundation of complex formulas. The present study will facilitate the quality control of Danning Tablet formulas as well as the individual herbs.
\end{abstract}

Keywords: Danning Tablets; Rhei Radix et Rhizoma; Polygoni Cuspidati Rhizoma et Radix; anthraquinones; UPLC-DAD-ESI-MS/MS; traditional Chinese medicine

\section{Introduction}

Herbal medicines have been used over thousands of years as alternative medicines or health products in China and many other countries, such as Korea, Japan, India, as well as in Western societies. Nowadays it well recognized that the biological activities of herbal medicines are the sum contribution of the polyvalent effects of their co-existing components. Therefore, great attention should be paid to the quality assessment of herbal medicines and formulas in order to guarantee their efficacy and safety.

Danning Tablets are a traditional Chinese formula showing a broad range of clinical applications in hepatobiliary diseases such as chronic cholecystitis, gallstones, constipation, and non-alcoholic fatty liver [1-3]. It is proven to have anti-inflammatory, and anti-stone properties, and to improve 
hepatic steatosis thus protecting the liver and gall bladder from injuries [4-6]. It is officially recorded in the Chinese Pharmacopoeia and consists of seven herbs according to traditional Chinese medicine formulation theory, i.e., Rhei Radix et Rhizoma (RRR), Polygoni Cuspidati Rhizoma et Radix (PCRR), Citri Reticulatae Pericarpium (CRP), Citri Reticulatae Pericarpium Viride (CRPV), Curcumae Radix (CR), Crataegi Fructus (CF) and Imperatae Rhizoma (IR). In the formula, RRR and PCRR are regarded as the Emperor (Jun) drugs, which means that RRR and PCRR are the major herbs responsible for the therapeutic effects of Danning Tablet in liver and gall bladder diseases. As reported, various components with pharmacological actions have been found in the formula, mainly anthraquinone derivatives such as emodin, chrysophanol, rhein, aloe-emodin, physcion and their glucosides $[7,8]$. Besides, flavonoids and stilbenes are also found in the formula. These two kinds of compounds are dose-dependently responsible for the protective effect of the formula on ANIT-induced liver injury with cholestasis in rats, which is related to the attenuation of oxidative stress in the liver tissue and neutrophil infiltration [9].

Danning Tablet formulations are prepared from seven medicinal herbs from different origins, each of which contains a diverse chemical profile. Therefore, the complete chemical profiling of the formulae is a rather complex problem, and it is undoubtedly a big challenge to identify the chemical markers with biological activity in such a highly complicated system. However, the knowledge about the chemicals in the formula is urgently needed for: (1) better understanding of its pharmacological mechanism(s) of action and (2) quality control of the formula via monitoring the multiple components. Therefore, great attention should be paid on characterizing the bioactive constituents in the formula.

Traditional quality control methods are mainly based on quantifying a single marker substance. Recently, chromatographic fingerprints have shown great advantage over traditional methods in mapping the entire metabolic profile of herbal medicines. In the last decade, liquid chromatography coupled with mass spectrometry (LC-MS) has become a powerful technique for the analysis of complex botanical extracts [10]. However, ultra-high performance liquid chromatography coupled to diode array detection and mass spectrophotometer (UPLC-DAD-MS) has recently been widely used in this area because it can achieve both higher sensitivity and shorter analysis times [11], which is essential for efficient analysis of trace amounts of chemicals. UPLC uses high pressure pumps to accommodate the use of sub-2 $\mu \mathrm{m}$ particle size columns, which can contribute to robust and rapid sample analysis [12]. DAD provides abundant information for structural elucidation of the compounds when it is integrated with tandem mass spectrometry. The electrospray ionization (ESI) source is preferred for its high ionization efficiency for the majority of chemical structures, such as phenolic compounds [13]. Hence, the combined technique of UPLC-DAD-ESI-MS/MS facilitates rapid and accurate identification of chemical compounds in complex Chinese medicines and formulas.

A chemical fingerprint and a simultaneous analysis of eight bioactive compounds in Danning Tablets were reported [14,15], which were inadequate to clearly reflect the intrinsic properties of such a complex formula containing seven botanical drugs. Besides, the bioactive constituents of Danning Tablets are still not clear. In the present study, we aimed to identify the structures and sources of polyphenols in the formula, including anthraquinones, anthrones, naphthalene, stilbenes and flavonoids. It was found that among all the 32 chemicals identified in the formula, 24 compounds were generated from RRR or PCRR, which are the major drugs responsible for the therapeutic effects of this formula. The anthraquinones profile, i.e., free anthraquinones, anthraquinone glycosides, anthrones and bianthrones, may serve as a diagnostic chemical marker for the quality assessment of Danning Tablets and provide information for a better understanding of the biological activities.

\section{Results and Discussion}

\subsection{Optimization of the UPLC and MS Conditions}

Danning Tablet is specially formulated using seven kinds of herbs from different origins. A vast number of chemical components co-exist in the formula, which makes the identification of 
the bioactive components more challenging. Therefore, the analysis conditions should be optimized to obtain chromatograms with good separation as well as sensitivity.

Firstly, parameters including column types, column temperatures, mobile phase, elution program, flow rates and detection wavelengths were investigated. Among the columns tested, T3 column $(2.1 \mathrm{~mm} \times 100 \mathrm{~mm}, 1.8 \mu \mathrm{m}$, Waters, Milford, MA, USA) was proved to be better than another two, i.e., a C8 column $(2.1 \mathrm{~mm} \times 100 \mathrm{~mm}, 1.8 \mu \mathrm{m}$, Waters $)$ and an ODS column $(2.0 \mathrm{~mm} \times 75 \mathrm{~mm}, 1.6 \mu \mathrm{m}$, Shimadzu, Nakagyo, Kyoto, Japan). The best separation was achieved when the column temperature was set at $35^{\circ} \mathrm{C}$ other than 30 and $40^{\circ} \mathrm{C}$. Formic acid $(0.1 \%)$ was used to improve the chromatographic behavior and to reduce the peak tailing. Five wavelengths were tested, i.e., $210 \mathrm{~nm}, 254 \mathrm{~nm}, 266 \mathrm{~nm}$, $280 \mathrm{~nm}$ and $346 \mathrm{~nm}$. And the best separation with most abundant peak number and highest intensities was achieved at $266 \mathrm{~nm}$ (Figure 1). Besides, better separation was obtained when the flow rate was lower, i.e., at $0.2 \mathrm{~mL} / \mathrm{min}$.

(a)
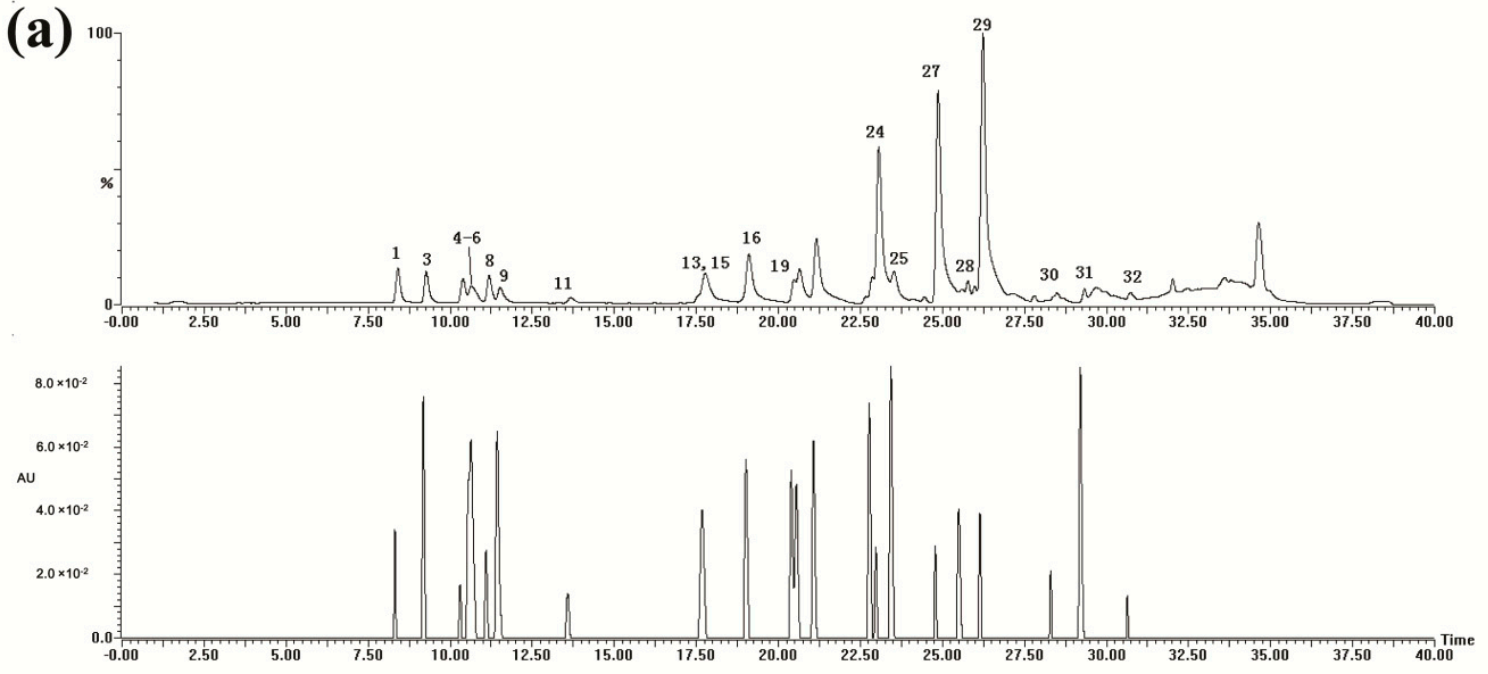

(b)
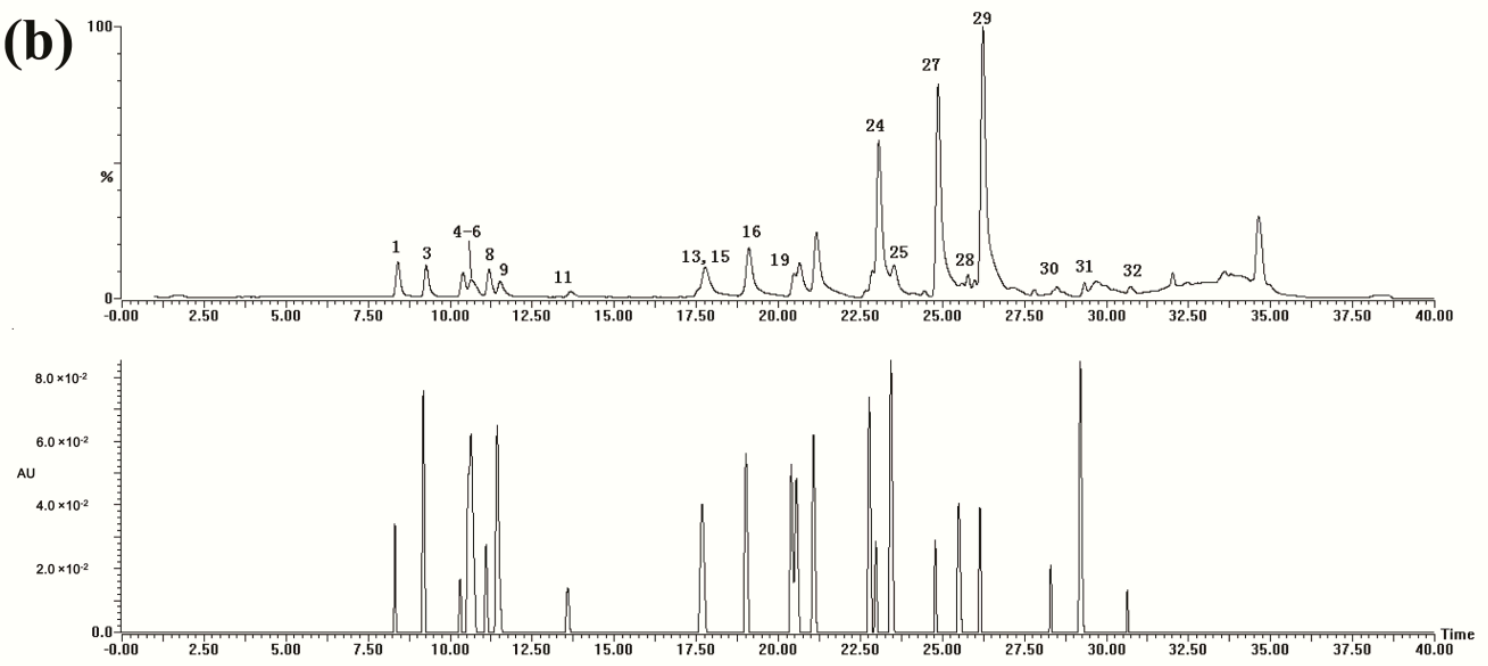

Figure 1. UPLC-DAD-ESI-MS chromatograms of standard reference mixture (a) and Danning Tablets sample (b) (Upper panel, LC-MS chromatogram at positive ion mode; lower panel, LC-UV chromatogram at $266 \mathrm{~nm}$. Peaks 1-32 were same as those in Table 1). 
Table 1. Chemicals characterized in Danning tablets by UPLC-DAD-ESI-MS/MS analysis.

\begin{tabular}{|c|c|c|c|c|c|c|c|}
\hline Peak No. & $t_{R}(\min )$ & $\mathrm{UV}_{\lambda}(\mathrm{nm})$ & MW & {$[\mathrm{M}+\mathrm{H}]^{+}$} & $\mathrm{CE}(\mathrm{eV})$ & MS/MS Fragmentation & Identification \\
\hline \multicolumn{8}{|c|}{ Stilbenes } \\
\hline 1 & 8.52 & 230,305 & 390 & 391 & 20 & 229 & Piceid $^{\text {a }}$ \\
\hline 8 & 11.46 & 230,305 & 228 & 229 & 30 & $211,183,165,135,119$ & Resveratrol ${ }^{\mathrm{a}}$ \\
\hline \multicolumn{8}{|c|}{ Anthraquinones } \\
\hline 2 & 9.4 & $256,280,430$ & 432 & 433 & 25 & $271,253,241,225,213,197$ & Aloe-emodin-O-glucoside isomer \\
\hline 7 & 11.10 & $258,280,430$ & 446 & 447 & 25 & $285,267,241,239,213,211,185$ & $\begin{array}{l}\text { Aloe-emoamn--g-glucosiae somer } \\
\text { Rhein-O-glucoside }\end{array}$ \\
\hline 10 & 12.14 & $\begin{array}{l}258,280,430 \\
256,280,430\end{array}$ & $\begin{array}{l}446 \\
432\end{array}$ & 433 & 30 & $\begin{array}{l}28,261,253,241,225,213,197 \\
271\end{array}$ & Aloe-emodin-O-glucoside isomer \\
\hline 12 & 15.97 & $256,280,430$ & 432 & 433 & 25 & $271,253,243,229,225,197$ & Emodin-O-glucoside \\
\hline 17 & 19.60 & $256,285,430$ & 416 & 417 & 25 & $255,237,227,209,181$ & Chrysophanol 1-O-glucoside \\
\hline 18 & 19.97 & $256,285,430$ & 416 & 417 & 25 & $255,237,227,209,181$ & Chrysophanol 8-O-glucoside \\
\hline 19 & 20.53 & $256,282,430$ & 432 & 433 & 25 & $271,253,243,229,225,197$ & Emodin $8-O-\beta$-D-glucoside ${ }^{a}$ \\
\hline 21 & 22.02 & $256,284,430$ & 446 & 447 & 30 & $285,270,267,252,242,239,211$ & Physcion 1-O-glucoside \\
\hline 23 & 22.71 & $256,284,430$ & 446 & 447 & 30 & $285,270,267,252,242,239,211$ & Physcion 8-O-glucoside \\
\hline 25 & 23.71 & $256,280,430$ & 270 & 271 & 27 & $253,241,225,213,197$ & Aloe-emodin a \\
\hline 28 & 25.52 & $258,280,431$ & 284 & 285 & 25 & $267,241,239,213,211,185$ & Rhein $^{\mathrm{a}}$ \\
\hline 30 & 28.52 & $265,287,437$ & 270 & 271 & 27 & $253,243,229,225,197$ & Emodin ${ }^{a}$ \\
\hline 31 & 29.41 & $257,287,429$ & 254 & 255 & 25 & $237,227,209,181$ & Chrysophanol a $^{\text {a }}$ \\
\hline 32 & 30.78 & $265,284,434$ & 284 & 285 & 27 & $270,267,252,242,239,211$ & Physcion $^{\mathrm{a}}$ \\
\hline \multicolumn{8}{|c|}{ Anthrones } \\
\hline 4 & 10.92 & 267,357 & 863 & $270^{\mathrm{b}}$ & 20 & 270 & Sennoside $\mathrm{B}^{\mathrm{a}}$ \\
\hline 9 & 11.73 & 268,322 & 849 & $256^{\mathrm{b}}$ & 20 & 256 & Sennoside $C^{a}$ \\
\hline 11 & 14.07 & 268,341 & 863 & $270^{\mathrm{b}}$ & 20 & 270 & Sennoside $A^{\text {a }}$ \\
\hline 15 & 18.16 & $269,296,358$ & 418 & 419 & 20 & $257,239,211$ & Aloin ${ }^{\mathrm{a}}$ \\
\hline \multicolumn{8}{|c|}{ Naphthalenes } \\
\hline 14 & 18.14 & $246,265,339$ & 408 & 409 & 25 & $247,229,214,201$ & Torachrysone-O-glucoside isomer \\
\hline 20 & 20.92 & $246,265,339$ & 408 & 409 & 25 & $247,229,214,201$ & Torachrysone-O-glucoside isomer \\
\hline \multicolumn{8}{|c|}{ Flavonoids } \\
\hline 3 & 9.42 & 268,341 & 432 & 433 & 20 & 313,283 & Vitexin $^{a}$ \\
\hline 5 & 11.02 & 255,355 & 464 & 465 & 20 & 303 & Hyperoside $^{\text {a }}$ \\
\hline 6 & 11.03 & 231,284 & 610 & 611 & 15 & 449,303 & Hesperidin ${ }^{a}$ \\
\hline 13 & 18.12 & 255,371 & 302 & 303 & 25 & $285,275,257,247,229,219,201$ & Quercetin $^{\text {a }}$ \\
\hline 16 & 19.54 & 253,350 & 286 & 287 & 30 & $269,241,179,161,153,135$ & Luteolin ${ }^{\mathrm{a}}$ \\
\hline 22 & 22.62 & 271,340 & 372 & 373 & 25 & $358,343,329$ & Isosinensetin \\
\hline 24 & 23.19 & 288,339 & 372 & 373 & 25 & $358,343,329,312,297$ & Sinensetin $^{\mathrm{a}}$ \\
\hline 26 & 24.17 & 270,335 & 342 & 343 & 25 & $328,313,285$ & Tetramethyl-O-isoscutellarein \\
\hline 27 & 25.02 & 271,336 & 402 & 403 & 25 & $388,373,355,342,327$ & Nobiletin ${ }^{\mathrm{a}}$ \\
\hline 29 & 26.35 & 272,326 & 372 & 373 & 25 & $358,343,312,297$ & Tangeretin ${ }^{a}$ \\
\hline
\end{tabular}

${ }^{\mathrm{a}}$ Means the chemical was authorized by standard reference; ${ }^{\mathrm{b}}$ Means the $m / z$ was responsible for $\left[\mathrm{M}+\mathrm{H}-2 \mathrm{Glu}-\mathrm{C}_{15} \mathrm{H}_{9} \mathrm{O}_{5}\right]^{+}$; $\mathrm{CE}$ means collision energy used for MS/MS fragmentation. 
For ESI-MS detection, the positive ion mode was selected for its better sensitivity and separation than the negative ion mode. As results, the condition was optimized as described in the Experimental Section. The LC-DAD-MS chromatogram of 20 reference standards is shown in Figure 1a, which shows clearly the separation of all standard references. A typical chromatogram of a Danning Tablets sample is shown in Figure $1 b$.

\subsection{UPLC-DAD-ESI-MS/MS Analysis of Compounds in Danning Tablets}

A total of 32 compounds were identified by interpretation of their $t_{R}$ value, $U V$ absorbance, molecular weight, and characteristic MS/MS fragment ions. All the compounds could be classified into five groups: anthraquinones, anthrones, naphthalenes, stilbenes and flavonoids. Twenty compounds were unambiguously confirmed by comparison with their standard references (Table 1).

Standard references for five anthraquinones and one glycoside, i.e., aloe-emodin, rhein, emodin, chrysophanol, physcion, and emodin 8-O- $\beta$-D-glucoside, were used in the UPLC-DAD-MS/MS analysis to obtain general information about the free anthraquinones and their glycosides (Figure 2 and Figure S1 in the Supplementary Materials). A great similarity was found in their UV absorption and MS/MS fragmentation. Firstly, both the free anthraquinones and the glycosides exhibited characteristic maximum absorptions at 250-270, 280-290 and 425-440 nm. The glycosides firstly lost $162 \mathrm{Da}$, i.e., elimination of a glucosyl residue, to produce a predominant fragment with an $m / z$ equal to its corresponding free anthraquinone, which could be obviously observed even in their full scan MS spectra (Figure S2). Then, a series of losses of 18 and $28 \mathrm{Da}$ was typical for free anthraquinones containing hydroxyl $(\mathrm{OH})$ and carbonyl $(\mathrm{CO})$ groups on the benzene ring [16]. For example, emodin easily produced a $\mathrm{m} / \mathrm{z} 243$ peak by the elimination of $\mathrm{CO}$, which was then followed by loss of a $\mathrm{CH}_{2}$ group to give $m / z 229$. In the MS/MS spectrum of chrysophanol, a product ion at $m / z$ 227 was observed, which resulted from the direct loss of $\mathrm{CO}$ from $[\mathrm{M}+\mathrm{H}]^{+}$. Both the $m / z 229$ fragment for emodin and the $m / z 227$ one of chrysophanol were very stable and did not yield any further fragmentations. Because the C-9 carbonyl group has intramolecular hydrogen bonding with the C-1 and C-8 $\alpha$-hydroxyl groups it is difficult to cleave, therefore, the CO elimination possibly originated from the C-10 carbonyl group. The glucosyl residue of emodin $8-O-\beta$-D-glucoside was lost very easily to produce a moiety which was then fragmented in the same pattern as that of emodin. Free anthraquinones containing other functional groups on the benzene ring, such as $\mathrm{COOH}$, $\mathrm{CH}_{2} \mathrm{OH}, \mathrm{COH}_{3}$, lost these groups easily to produce the corresponding fragments. As seen in the MS/MS fragmentation of aloe-emodin, physcion and rhein, fragments of $m / z 241, \mathrm{~m} / z 270$ and $\mathrm{m} / z$ 241 were produced by the losses of $\mathrm{CH}_{2} \mathrm{O}, \mathrm{CH}_{3}$, and $\mathrm{CO}_{2}$, respectively (Figure 2 and Figure S1). Besides, these differences were also valuable for the identification of isomer pairs, such as emodin and aloe-emodin, physcion and rhein, as well as of their corresponding glycosides. Therefore, five free anthraquinones (peaks 25, 28, 30, 31 and 32) were identified as aloe-emodin, rhein, emodin, chrysophanol and physcion, respectively, by comparing their retention times, UV absorptions, and MS/MS fragmentation patterns with those of the standard references and literature data [16-18]. Besides, nine anthraquinone glycosides (peaks 2, 7, 10, 12, 17, 18, 19, 21 and 23) were identified (Figure S3). Among them, peak $2\left(t_{R} 9.40 \mathrm{~min}\right)$ and $10\left(t_{R} 12.14 \mathrm{~min}\right)$ were tentatively characterized as aloe-emodin-O-glucoside isomers, showing characteristic MS/MS fragment ions at $m / z 271,253,241$, 225, 213 and 197, which was similar to the MS/MS fragmentation behavior of aloe-emodin, i.e., $m / z$ 253, 241, 225, 213 and 197. However, the identification of the glucosylation position was not possible as too many possible positions exist [16]. Peak $7\left(t_{\mathrm{R}} 11.10 \mathrm{~min}\right.$ ) was fragmented to produce a peak with $\mathrm{m} / z$ 285 , which was further fragmented in a similar pattern as that of rhein, i.e., producing ions at $m / z 267$, 241, 239, 213211 and 185. Thus, peak 7 was tentatively identified as rhein-O-glucoside but without specifying the glucosyl position because at least two possible positions were reported [16]. Similarly, peaks $19\left(t_{R} 20.53 \mathrm{~min}\right)$ and $12\left(t_{R} 16.00 \mathrm{~min}\right)$ were identified as emodin-8-O- $\beta$-D-glucoside and its isomer, respectively. Peaks $17\left(t_{R} 19.60 \mathrm{~min}\right)$ and $18\left(t_{R} 19.95 \mathrm{~min}\right)$ were tentatively characterized as 
Molecules 2016, 21, 631

6 of 13

chrysophanol-O-glucoside isomers [16]. Meanwhile, peak $21\left(t_{\mathrm{R}} 22.02 \mathrm{~min}\right)$ and $23\left(\mathrm{t}_{\mathrm{R}} 22.71 \mathrm{~min}\right)$ were tentatively identified as physcion 1-O-glucoside and physcion 8-O-glucoside, respectively (Figure S2).

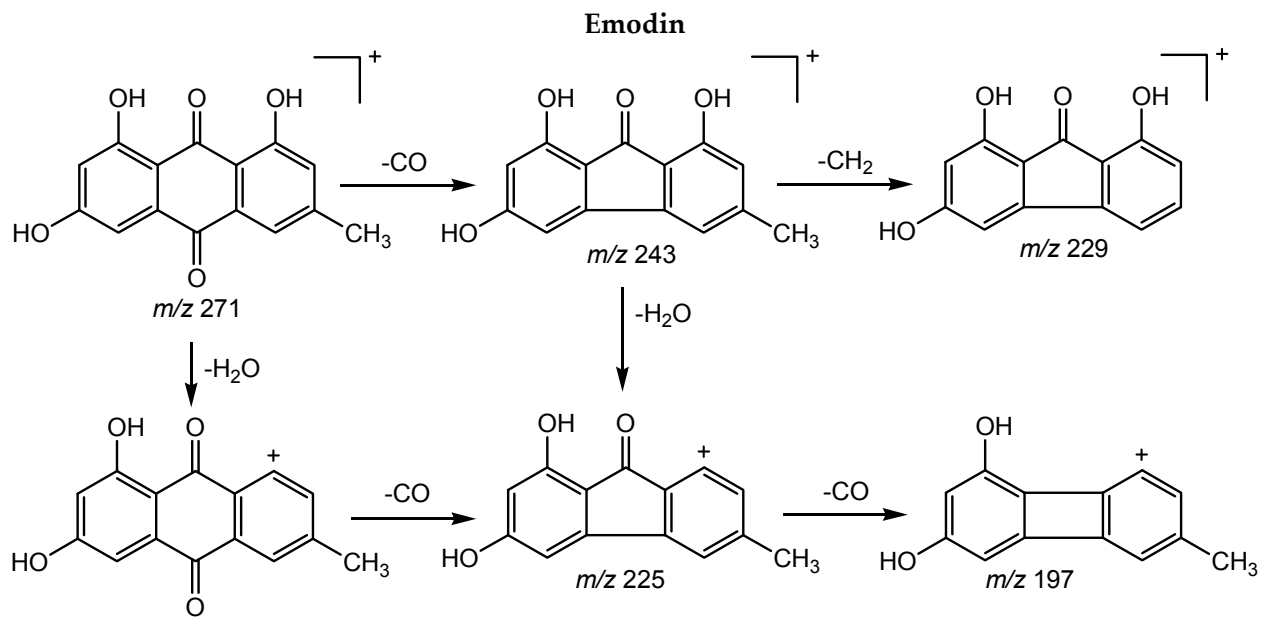

$m / z 253$

Aloe-emodin<smiles>C[C@H](Cc1cc(O)c2c(c1)C(=O)c1cccc(O)c1C2=O)OCC[PH+](C)C</smiles><smiles>Cc1cccc2c1C(=O)c1c(O)cccc1C2=O</smiles><smiles>[Z16]c1cccc(O)c1C(=O)c1c(C)cccc1O</smiles>

$m / z 271$

$m / z 241$
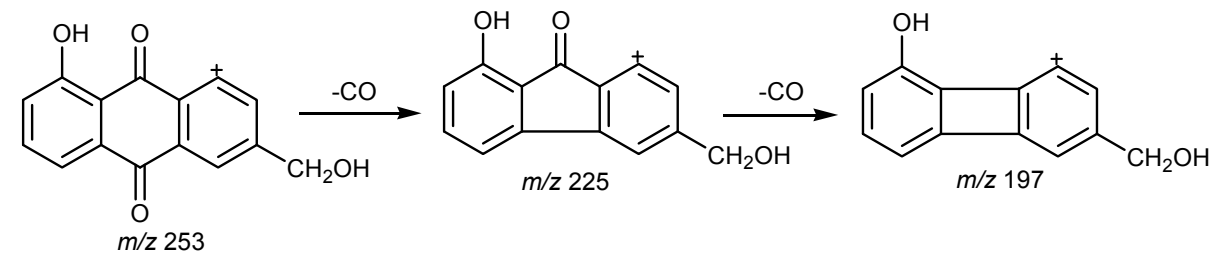

$\mathrm{m} / \mathrm{z} 225$

Rhein<smiles>C[CH+]CC(=O)c1cc(O)c2c(c1)C(=O)c1cccc(O)c1C2=O</smiles>
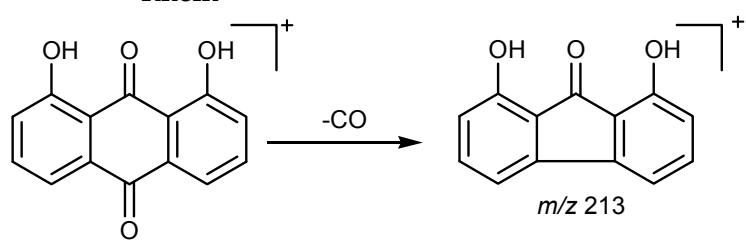

$m / z 285$

$m / z 241$
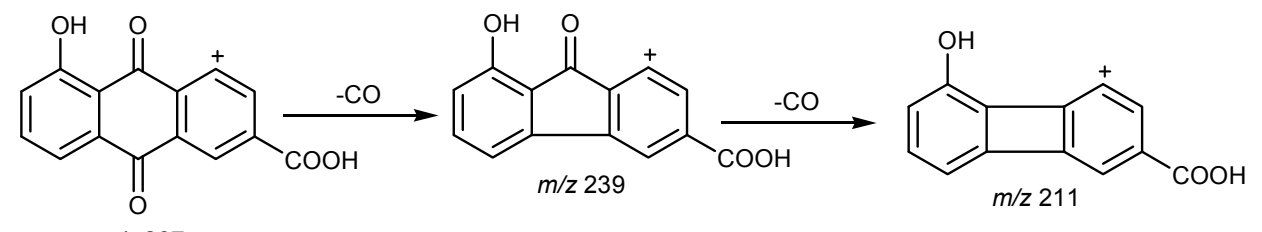

$m / z 267$

Figure 2. Cont. 


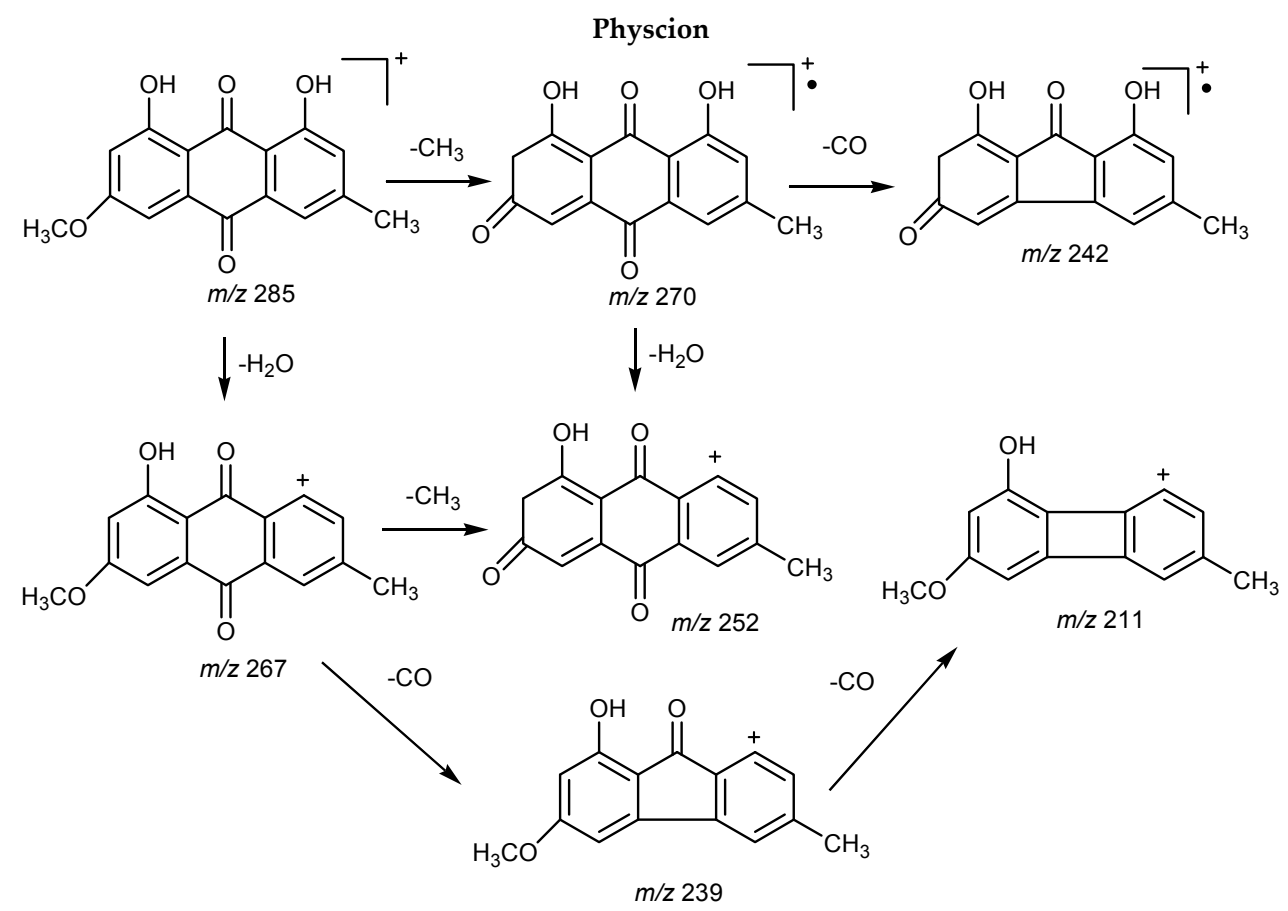

Chrysophanol
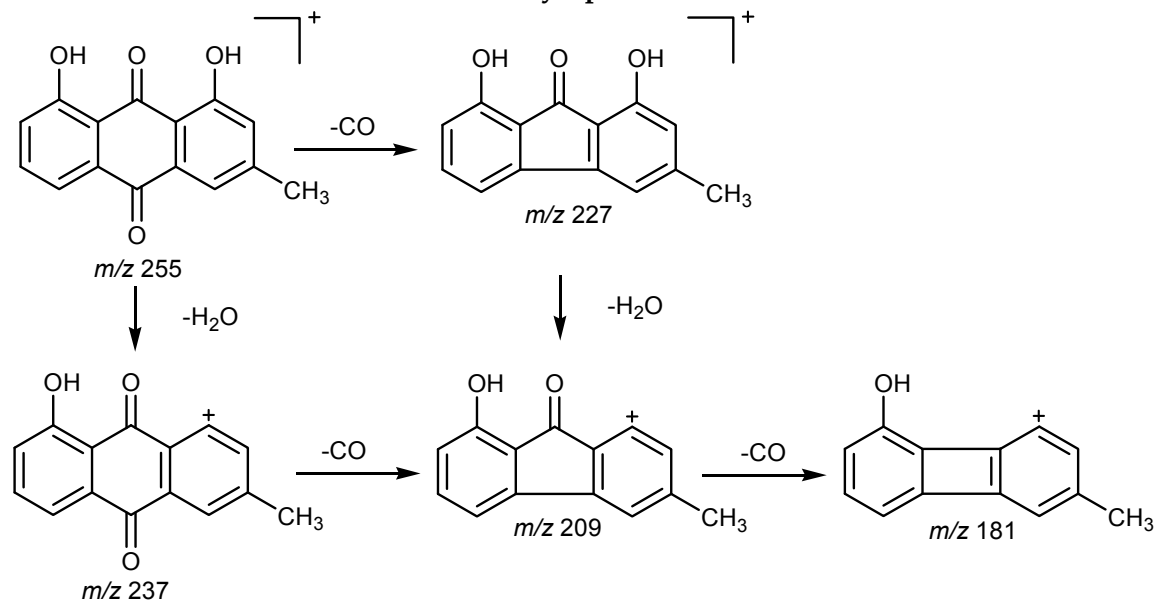

Figure 2. Proposed MS/MS fragmentation pathways of five free anthraquinones standard references.

Four glycosyl anthrone standards, i.e., sennoside A, sennoside B, sennoside C, and aloin, were applied in the UPLC-DAD-MS/MS analysis to get general information about these components (Figure S1). The characteristic UV maximum absorptions for these compounds were found at 260-275 and 320-360 nm, which facilitated their preliminary identification (Table 1). All three bianthrones, i.e., sennoisde A, B and C, were positively ionized to lose two glycosyl groups and cleaved at the $\mathrm{C} 10-\mathrm{C} 10^{\prime}$ bond to produce a significant ion at $m / z 270$, which was relatively hard to further fragment and thus could be used for rapid identification of anthrones in the present study. Although being similar in structure, these three diglycosyl anthrones showed different retention behavior on the column and peaks $4\left(t_{R} 10.92 \mathrm{~min}\right), 9\left(t_{R} 11.73 \mathrm{~min}\right)$, and $11\left(t_{R} 14.07 \mathrm{~min}\right)$, were identified as sennoside $B$, sennoside C and sennoside A [16]. In addition to the maximum UV absorptions at 269 and $358 \mathrm{~nm}$, aloin also showed a specific absorption at $296 \mathrm{~nm}$. It was fragmented to lose one glycosyl group and produced an ion at $m / z 257$, which further lost $\mathrm{H}_{2} \mathrm{O}$ and $\mathrm{CO}$ to produce ions at $m / z 239$ and 211, respectively. Therefore, peak $15\left(t_{R} 18.11 \mathrm{~min}\right)$ was identified as aloin [19]. 
Two peaks, i.e., peak $14\left(\mathrm{t}_{\mathrm{R}} 18.14 \mathrm{~min}\right)$ and peak $20\left(\mathrm{t}_{\mathrm{R}} 20.92 \mathrm{~min}\right)$, exhibited maximum UV absorptions at 246, 265 and $323 \mathrm{~nm}$. Besides, both of them gave the same fragment ions at $m / z$ 409, 431 and 247, suggesting common base peaks at $m / z 409\left([\mathrm{M}+\mathrm{H}]^{+}\right)$and the existence of a glycosyl group (Table 1). The ion at $m / z 247$ further fragmented to produce ions at $m / z 229,214$ and 201, which were caused by successive losses of $\mathrm{H}_{2} \mathrm{O}$ and $\mathrm{CO}$ from the $m / z 247$ ion, and loss of $\mathrm{CO}$ from the ion at $m / z 229$. Therefore, peaks 14 and 20 were tentatively identified as torachrysone-O-glucoside or its isomer according to the reported data [20].

Two stilbenes standards, i.e., piceid and resveratrol, were used for the UPLC-DAD-MS/MS analysis (Figure S4). Characteristic maximum UV absorptions were found at 230 and $305 \mathrm{~nm}$ (Table 1). Piceid gave a $[\mathrm{M}+\mathrm{H}]^{+}$ion at $m / z 391$ and a product ion of $m / z 229$ by elimination of a glucosyl residue. Resveratrol, the aglycon of piceid, gave a $[\mathrm{M}+\mathrm{H}]^{+}$ion at $m / z 229$ and produced fragments at $m / z 211$, $183,165,135$ and 119. The ions at $m / z 211$ and 183 were produced by successive losses of $\mathrm{H}_{2} \mathrm{O}$ and $\mathrm{CO}$ from the parent ion. Meanwhile, the ions at $m / z 135$ and 119 correspond to the cleavage of the A-B and C-D bonds of the parent ion at $m / z 229$. Besides, the ion at $m / z 165$ was caused by loss of $\mathrm{H}_{2} \mathrm{O}$ from the ion at $m / z$ 183. Therefore, peaks $1\left(t_{R} 8.52 \mathrm{~min}\right)$ and $8\left(t_{R} 11.46 \mathrm{~min}\right)$ were identified as piceid and resveratrol, respectively, by comparing their retention times, UV absorption, MS and MS/MS fragmentation patterns with those of the reference compounds. No other stilbenes were detected in the formula.

In total, ten flavonoids were identified in Danning Tablets, including seven flavone structures, one flavanone structure and two flavonol structures (Figure S5). All of these compounds exhibited two maximum UV absorptions at 240-285 and 300-400 nm originating from their A- and B-rings, which are typical for flavonoids. Eight standard references were investigated to get the characteristic fragmentations for each subtype. Generally, loss of $28 \mathrm{Da}(\mathrm{CO})$ and $44 \mathrm{Da}\left(\mathrm{CO}_{2}\right)$ from the C-ring was common for all the standard references investigated, while loss of $15 \mathrm{Da}\left(\mathrm{CH}_{3}\right)$ was specific for compounds those contain a methoxyl group. Besides, the structures with different aglycones, i.e., methoxyl substitution, hydroxyl substitution, C-glycosyl groups and O-glycosyl groups, showed different MS/MS fragmentation patterns [21-26]. As a result, peaks $3\left(t_{R} 9.42 \mathrm{~min}\right), 5\left(t_{R} 11.02 \mathrm{~min}\right)$, $6\left(t_{R} 11.03 \mathrm{~min}\right), 13\left(t_{R} 18.12 \mathrm{~min}\right), 16\left(t_{R} 19.54 \mathrm{~min}\right), 24\left(t_{R} 23.19 \mathrm{~min}\right), 27\left(t_{R} 25.02 \mathrm{~min}\right)$ and 29 $\left(t_{R} 26.35 \mathrm{~min}\right)$ were unequivocally identified as vitexin, hyperoside, hesperidin, quercetin, luteolin, sinensetin, nobiletin and tangeretin, respectively. Peak $22\left(\mathrm{~m} / z 373\right.$ at $\left.t_{R} 22.62 \min \right)$ showed a specific flavonoid UV absorption. Besides, peak 22 fragmented in a way similar to that of sinensetin, i.e. producing ions at $m / z 343$ and 329. Therefore, peak 22 was tentatively identified as isosinensetin according to [27,28]. Besides, peak $26\left(\mathrm{~m} / \mathrm{z} 343\right.$ at $\left.\mathrm{t}_{\mathrm{R}} 24.17 \mathrm{~min}\right)$ was tentatively identified as tetramethyl-O-isoscutellarein by comparing its MS/MS fragmentation to that of the reported data [28].

\subsection{Confirmation of the Source of the Compounds Identified in the Formula}

Furthermore, the sources of these 32 compounds were identified by comparisons between the complete formula containing all seven herbs, the formulae without certain herbs and each of the single herbs (Table 1). For example, a comparison was firstly made between the complete formula and the single RRR herb, and 21 compounds were identified as coming from RRR (Figure S6). However, when a further comparison was made between the complete formula, the revised formula consisting of six herbs (without RRR, Figure S7), and the single PCRR herb, 11 compounds were also found to exist in RRR, therefore, only 10 chemicals were identified to be uniquely sourced from RRR, including aloe-emodin-O-glucoside, sennoside $\mathrm{B}$, rhein-O-glucoside, sennoside $\mathrm{C}$, sennoside $\mathrm{A}$, chrysophanol 1-O-glucoside, chrysophanol 8-O-glucoside, rhein and chrysophanol. Similarly, 14 compounds were sourced from PCRR, among which only two chemicals, i.e., piceid and resveratrol, were unique to PCRR. Nine compounds were sourced from CRPV, among which six (vitexin, isosinensetin, sinensetin, tetramethyl-O-isoscutellarein, nobiletin and tangeretin) were unique to CRPV. Three compounds were found in $\mathrm{CF}$, among which two chemicals were uniquely found in $\mathrm{CF}$, namely hyperoside and quercetin. What's more, 24 compounds were generated from RRR or PCRR, including 14 anthraquinones, 
four anthrones, two stilbenes, two naphthalenes, and two flavonoids. Twelve were found to be co-existing compounds in RRR and PCRR (Figure 3). It's known that RPP and PCRR are the Emperor (Jun) drugs in the Danning Tablet formula, indicating the importance of RPP and PCRR for its therapeutic effects. Therefore, the traditional formulation theory is consistent with the chemical foundation of the formula as revealed in our present study.

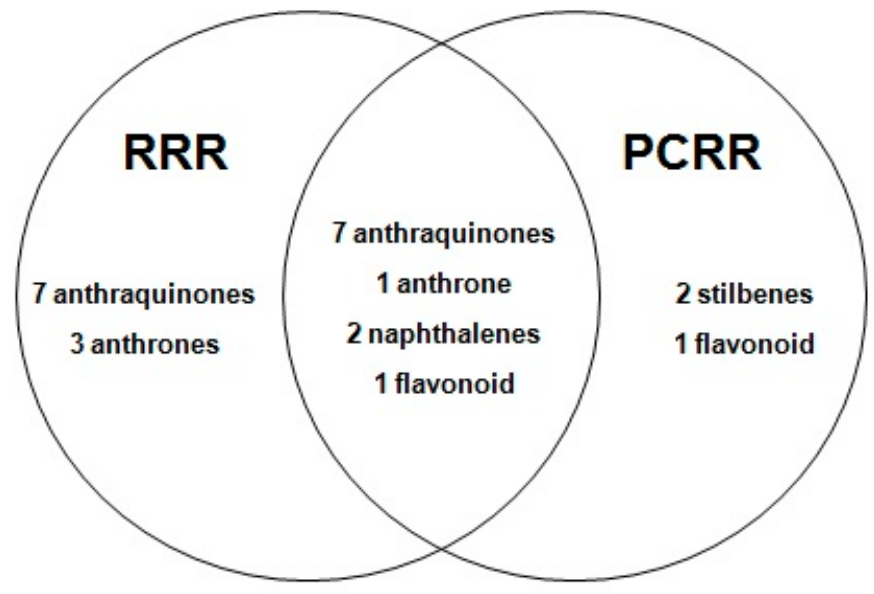

Figure 3. The compounds identified in Rhei Radix et Rhizoma (RRR) and Polygoni Cuspidati Rhizoma et Radix (PCRR).

\section{Experimental Section}

\subsection{Materials}

HPLC-grade methanol and formic acid (96\%) were obtained from Tedia Co. (Fairfield, OH, USA). Water was prepared by a Milli-Q system (Millipore, MA, USA). All other reagents were of analytical grade and were purchased from Tianjin Damao Chemical Reagent Factory (Tianjin, China). Twenty reference compounds (Table 2) were purchased from the National Institute for Food and Drug Control (Beijing, China). The herbs for preparation of Danning Tablets were provided by Shanghai Hutchison Pharmaceuticals (Shanghai, China). Danning Tablets are made with seven herbal drugs, i.e., Rhei Radix et Rhizoma (RRR), Polygoni Cuspidati Rhizoma et Radix (PCRR), Citri Reticulatae Pericarpium (CRP), Citri Reticulatae Pericarpium Viride (CRPV), Curcumae Radix (CR), Crataegi Fructus (CF) and Imperatae Rhizoma (IR), and some excipients. The amounts of each composition for 1000 tablets are as follows: RRR, 48 g; PCRR, 720 g; CRPV, 288 g; CRP, 288 g; CR, 432 g; CF, 720 g; IR, 432 g; calcium sulphate, $6.25 \%$; D-(+)-sucrose, $7.5 \%$; povidone $\mathrm{K} 30,1.25 \%$; magnesium stearate, $1 \%$; sodium bicarbonate, $2 \%$. Danning Tablets and all herbs were stored in the dark at room temperature and verified by the Quality Inspection Center of Shanghai Hutchison Pharmaceuticals. Qualified inspection reports were provided according to the Chinese Pharmacopoeia standards. The seven revised formulas of Danning Tablets with only six herbs were prepared according to the formulation of the complete formula but with exclusion of each single herb, respectively.

\subsection{Sample Preparation}

The Danning Tablets were firstly powdered and $1 \mathrm{~g}$ of the powder was extracted twice with $50 \mathrm{~mL}$ of $95 \%$ ethanol under ultrasound for $60 \mathrm{~min}$. After filtering, the filtrates were combined and $95 \%$ ethanol was added to the volumetric flask up to $100 \mathrm{~mL}$. A precisely measured aliquot (25 mL) was evaporated and methanol added up to $10 \mathrm{~mL}$. The supernatant solution was filtrated through a syringe filter $(0.22 \mu \mathrm{m})$ and aliquots $(2 \mu \mathrm{L})$ were injected into the chromatographic system for analysis. About $0.5 \mathrm{~g}$ of the powdered single herb was accurately measured and prepared following the method described above for analysis. 
Table 2. Chemical structures of the twenty standard references.

(a) Free anthraquinones and their glucosides<smiles>[R]c1cc(O)c2c(c1)C(=O)c1cc([R])cc(O)c1C2=O</smiles>

\begin{tabular}{|c|c|c|c|c|}
\hline No. & Compound Name & $\mathbf{R}_{1}$ & $\mathbf{R}_{2}$ & $\mathbf{R}_{3}$ \\
\hline 1 & Chrysophanol & $\mathrm{H}$ & $\mathrm{CH}_{3}$ & $\mathrm{H}$ \\
\hline 2 & Emodin & $\mathrm{OH}$ & $\mathrm{CH}_{3}$ & $\mathrm{H}$ \\
\hline 3 & Aloe-emodin & $\mathrm{H}$ & $\mathrm{CH}_{2} \mathrm{OH}$ & $\mathrm{H}$ \\
\hline 4 & Rhein & $\mathrm{H}$ & $\mathrm{COOH}$ & $\mathrm{H}$ \\
\hline 5 & Physcion & $\mathrm{OCH}_{3}$ & $\mathrm{CH}_{3}$ & $\mathrm{H}$ \\
\hline 6 & Emodin $8-O-\beta$-D-glucoside & $\mathrm{OH}$ & $\mathrm{CH}_{3}$ & Glu \\
\hline
\end{tabular}

(b) Anthrones<smiles>O=C(O)c1cc(O)c2c(c1)C(CCCOc1ccccc1)c1cc(Br)cc(O)c1C2=O</smiles><smiles>CC1c2cccc(O)c2C(=O)c2c(O)cc(CO)cc21</smiles>

10 Aloin

\begin{tabular}{ccc}
\hline No. & Compound Name & R \\
\hline 7 & Sennoside A $\left(10,10^{\prime}\right.$-trans $)$ & $\mathrm{COOH}$ \\
8 & Sennoside B $\left(10,10^{\prime}\right.$-meso $)$ & $\mathrm{COOH}$ \\
9 & Sennoside C $\left(10,10^{\prime}\right.$-trans $)$ & $\mathrm{CH}_{2} \mathrm{OH}$ \\
\hline
\end{tabular}

(c) Stilbenes

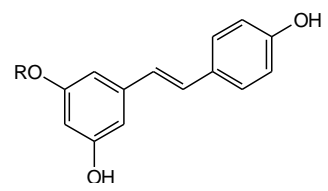

\begin{tabular}{ccc}
\hline No. & Compound Name & R \\
\hline 11 & Piceid & Glu \\
12 & Resveratrol & H \\
\hline
\end{tabular}

(d) Flavonoids

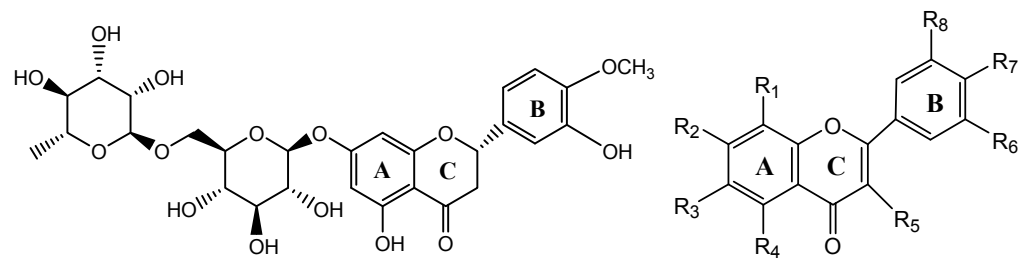

13 Hesperidin

\begin{tabular}{|c|c|c|c|c|c|c|c|c|c|}
\hline No. & Compound Name & $\mathbf{R}_{1}$ & $\mathbf{R}_{2}$ & $\mathbf{R}_{3}$ & $\mathbf{R}_{4}$ & $\mathbf{R}_{5}$ & $\mathbf{R}_{6}$ & $\mathbf{R}_{7}$ & $\mathbf{R}_{8}$ \\
\hline 14 & Luteolin & $\mathrm{H}$ & $\mathrm{OH}$ & $\mathrm{H}$ & $\mathrm{OH}$ & $\mathrm{H}$ & $\mathrm{H}$ & $\mathrm{OH}$ & $\mathrm{OH}$ \\
\hline 15 & Nobiletin & $\mathrm{OCH}_{3}$ & $\mathrm{OCH}_{3}$ & $\mathrm{OCH}_{3}$ & $\mathrm{OCH}_{3}$ & $\mathrm{H}$ & $\mathrm{OCH}_{3}$ & $\mathrm{OCH}_{3}$ & $\mathrm{H}$ \\
\hline 16 & Sinensetin & $\mathrm{H}$ & $\mathrm{OCH}_{3}$ & $\mathrm{OCH}_{3}$ & $\mathrm{OCH}_{3}$ & $\mathrm{H}$ & $\mathrm{OCH}_{3}$ & $\mathrm{OCH}_{3}$ & $\mathrm{H}$ \\
\hline 18 & Vitexin & Glu & $\mathrm{OH}$ & $\mathrm{H}$ & $\mathrm{OH}$ & $\mathrm{H}$ & $\mathrm{H}$ & $\mathrm{OH}$ & $\mathrm{H}$ \\
\hline 19 & Quercetin & $\mathrm{H}$ & $\mathrm{OH}$ & $\mathrm{H}$ & $\mathrm{OH}$ & $\mathrm{OH}$ & $\mathrm{H}$ & $\mathrm{OH}$ & $\mathrm{OH}$ \\
\hline 20 & Hyperoside & $\mathrm{H}$ & $\mathrm{OH}$ & $\mathrm{H}$ & $\mathrm{OH}$ & OGlu & $\mathrm{H}$ & $\mathrm{OH}$ & $\mathrm{OH}$ \\
\hline
\end{tabular}




\subsection{Equipment and Chromatographic Conditions}

A Waters Acquity system (Waters Corp., Milford, MA, USA) was coupled with a triple-quadrupole tandem mass spectrometry, a gradient pump, an autosampler and a DAD detector. Chromatographic separation was carried out on a Waters ACQUITY UPLC HSS T3 column $(2.1 \mathrm{~mm} \times 100 \mathrm{~mm}, 1.8 \mu \mathrm{m})$ at a column temperature of $35^{\circ} \mathrm{C}$, with a flow rate of $0.2 \mathrm{~mL} / \mathrm{min}$. The mobile phase were composed of methanol (A) and 0.1\% formic acid (B) with a gradient program as follows: $0-3 \mathrm{~min}, 5 \%-16 \% \mathbf{A}$; 3-4.5 $\mathrm{min}, 16 \%-32 \%$ A; $4.5-6.5 \mathrm{~min}, 32 \%-40 \%$ A; $6.5-10 \mathrm{~min}, 40 \%-43 \% \mathrm{~A} ; 10-15 \mathrm{~min}, 43 \% \mathrm{~A} ; 15-17 \mathrm{~min}$, 43\%-52\% A; 17-21.5 min, 52\%-65\% A; 21.5-28 min, 65\%-85\% A; 28-30 min, 85\%-92\% A; 30-33 min, $92 \%-95 \%$ A. A pre-equilibration period of $6 \mathrm{~min}$ was used between individual run. The DAD detector was set in the range of 200-500 $\mathrm{nm}$. Mass spectrometry was performed in the ESI positive ion mode. Data acquisition was performed in full-scan, selective ions monitoring (SIR) and MS/MS modes in the range of $m / z$ 150-1000. The capillary voltage was optimized to $4 \mathrm{kV}$, and the cone voltage was $30 \mathrm{~V}$. The source temperature was set to $120^{\circ} \mathrm{C}$, and the desolvation temperature was $350{ }^{\circ} \mathrm{C}$, while the desolvation gas flow was set to $600 \mathrm{~L} / \mathrm{h}$, and the cone gas flow was $100 \mathrm{~L} / \mathrm{h}$.

\section{Conclusions}

A total of 32 compounds, including five free anthraquinones, nine anthraquinone glucosides, three dianthrone glycosides, one anthrone glycoside, two naphthalene glycosides, two stilbenes, and 10 flavonoids, were successfully identified from the traditional Chinese medicine formula Danning Tablets by UPLC-DAD-ESI-MS/MS by comparison with reference standards and their UV absorption features and MS/MS fragmentation patterns. Meanwhile, the source of these 32 compounds was identified by comparison among Danning tablets, revised Danning tablets lacking a single component and the single herbs. It was found that among all the 32 chemicals identified in the formula, 24 originated from Rhei Radix et Rhizoma (RRR) or Polygoni Cuspidati Rhizoma et Radix (PCRR), among which there were 14 anthraquinones and four anthrones. As reported, anthraquinone derivatives are the main chemicals responsible for the activity of the Danning Tablet formula. It's also known that RRR and PCRR are the major drugs responsible for the therapeutic effects of this formula. These two matched well, thus revealing the success of our proposed approach for illustrating the chemical foundation for the biochemical activities of traditional formulas.

The current developed method also achieved rapid identification of the chemical components in Danning Tablets thus providing detailed information for establishing a comprehensive quality control method. Furthermore, identification of the source of each component in Danning Tablets will also benefit the quality control of herbs, so as to achieve better quality control of Danning Tablets. In addition, it also provided a basis for profiling the active components of the formula in biological samples, such as serum, which would facilitate metabolism and pharmacokinetic studies of the formula to further illustrate the mechanism of action of the formula.

Supplementary Materials: Supplementary materials can be accessed at: http://www.mdpi.com/1420-3049/ 21/5/631/s1.

Acknowledgments: This work was financially supported by the Natural Science Foundations of China (81222053, 81303186), the Program for New Century Excellent Talents in University (NCET-12-1056), the China Post-doctoral Science Foundation (2013M531202) and Shanghai Science and Technology Commission Project (10DZ1970200) is gratefully acknowledged.

Author Contributions: Conceived and designed: Changsen Zhan, Li Yang, Zhengtao Wang; Conducted experiments: Changsen Zhan, Danping Shen; Contributed new reagents or analytic tools: Danping Shen; Performed data analysis: Changsen Zhan, Aizhen Xiong; Wrote the manuscript: Changsen Zhan.

Conflicts of Interest: The authors declare no conflict of interest 


\section{References}

1. Fan, J.G. Evaluating the efficacy and safety of Danning Pian in the short-term treatment of patients with non-alcoholic fatty liver disease: A multicenter clinical trial. Hepatobiliary Pancreat Dis. Int. 2004, 3, 375-380. [PubMed]

2. Fan, J.G.; Yuan, Z.L.; Xu, Z.J.; Jiang, H.Q. Clinical observation of Danning Tablet for 57 patients with habitual constipation. J. Modern Med. Health 2003, 19, 396-397.

3. Zhu, P.T.; Zhang, J.Z.; Wang, Y.S. Clinical Study on Treatment of chronic cholecystitis, gallstones by Danning Tablets. Shanghai J. Tradit. Chin. Med. 1990, 24, 18-20.

4. Ji, K.R.; Ji, F.; Wang, R.R.; Jiang, H.; Shi, W.J. Preventive effect and mechanism of Danning Tablet on the cholesterol gallstone. J. Hepatopanereatobiliay Surg. 2004, 16, 44-46.

5. Liu, R.H.; Chen, Z.L.; Li, T.J.; Liu, X.H.; Xu, R.L.; Xu, X.K.; Zhang, C.; Zhang, W.D. The protective effects of Danning Tablet on experimental liver injury in mice and rats. J. Pharm. Pract. 2007, 25, 147-149.

6. Zhu, P.T.; Xu, C.S.; Zhang, J.Z. Study on the inhibition of bile pigment stone by Danning Tablets. Shanghai J. Tradit. Chin. Med. 1990, 24, 1-7.

7. Kim, D.H.; Park, E.K.; Bae, E.A.; Han, M.J. Metabolism of rhaponticin and chrysophanol 8-O-beta-D-glucopyranoside from the rhizome of Rheum undulatum by human intestinal bacteria and their anti-allergic actions. Biol. Pharm. Bull. 2000, 23, 830-833. [CrossRef] [PubMed]

8. Lin, Y.L.; Wu, C.F.; Huang, Y.T. Effects of rhubarb on migration of rat hepatic stellate cells. J. Gastroenterol. Hepatol. 2009, 24, 453-461. [CrossRef] [PubMed]

9. Ding, L.L.; Zhang, B.F.; Dou, W.; Yang, L.; Zhan, C.S.; Wang, Z.T. Protective effect of Danning Tablet on acute livery injury with cholestasis induced by $\alpha$-naphthylisothiocyanate in rats. J. Ethnopharmacol. 2012, 140, 222-229. [CrossRef] [PubMed]

10. Cai, Z.; Lee, F.S.; Wang, X.R.; Yu, W.J. A capsule review of recent studies on the application of mass spectrometry in the analysis of Chinese medicinal herbs. J. Mass Spectrom. 2002, 37, 1013-1024. [CrossRef] [PubMed]

11. Gika, H.G.; Theodoridis, G.A.; Wilson, I.D. Liquid chromatography and ultra-performance liquid chromatography-mass spectrometry fingerprinting of human urine: Sample stability under different handling and storage conditions for metabonomics studies. J. Chromatogr. A 2008, 1189, 314-322. [CrossRef] [PubMed]

12. Nováková, L.; Matysová, L.; Solich, P. Advantages of application of UPLC in pharmaceutical analysis. Talanta 2006, 68, 908-918. [CrossRef] [PubMed]

13. Justesen, U. Collision-induced fragmentation of deprotonated methoxylated flavonoids, obtained by electrospray ionization mass spectrometry. J. Mass Spectrom. 2001, 36, 169-178. [CrossRef] [PubMed]

14. Liang, M.J.; Zhang, J.Y.; Liu, R.H.; Yan, S.K.; Zhang, W.D. Chemical Profile of Danning Tablets by LC-DAD Coupled with ESI-MS. Chromatographia 2007, 66, 107-110. [CrossRef]

15. Liu, R.; Zhang, J.; Liang, M.; Zhang, W.; Yan, S.; Lin, M. Simultaneous analysis of eight bioactive compounds in Danning Tablet by HPLC-ESI-MS and HPLC-UV. J. Pharm. Biomed. Anal. 2007, 43, 1007-1012. [CrossRef] [PubMed]

16. Ye, M.; Han, J.; Chen, H.; Zheng, J. Analysis of phenolic compounds in rhubarbs using liquid chromatography coupled with electrospray ionization mass spectrometry. J. Am. Soc. Mass Spectrom. 2007, 18, 82-91. [CrossRef] [PubMed]

17. Wu, H.F.; Chen, L.W.; Chen, C.H. Probing reactive sites for ion-molecule reactions of anthraquinones with dimethyl ether using an external source ion trap tandem mass spectrometer and computational chemistry. Rapid Commun. Mass Spectrom. 2001, 15, 1977-1987. [CrossRef] [PubMed]

18. Song, R.; Xu, L.; Xu, F.; Dong, H.; Tian, Y.; Zhang, Z. Metabolic analysis of rhubarb extract by rat intestinal bacteria using liquid chromatography-tandem mass spectrometry. Biomed. Chromatogr. 2011, 25, 417-426. [CrossRef] [PubMed]

19. Wu, X.F.; Ding, W.J.; Zhong, J.S.; Wan, J.Z.; Xie, Z.Y. Simultaneous qualitative and quantitative determination of phenolic compounds in Aloe barbadensis Mill by liquid chromatography-mass spectrometry-ion trap-time-of-flight and high performance liquid chromatography-diode array detector. J. Pharm. Biomed. Anal. 2013, 80, 94-106. [CrossRef] [PubMed] 
20. Dong, J.; Wang, H.; Wan, L.R.; Tuan, Y.S.; Chen, S.Z. Identification and determination of major constituents in Polygonum cuspidatum Sieb. et Zucc. by high performance liquid chromatography/ electrospray ionization-ion trap-time-of-flight mass spectrometry. Chin. J. Chromatogr. 2009, 27, 425-430.

21. Stevens, J.F.; Taylor, A.W.; Deinzer, M.L. Quantitative analysis of xanthohumol and related prenylflavonoids in hops and beer by liquid chromatography-tandem mass spectrometry. J. Chromatogr. A 1999, 832, 97-107. [CrossRef]

22. He, X.G. On-line identification of phytochemical constituents in botanical extracts by combined high-performance liquid chromatographic-diode array detection-mass spectrometric techniques. J. Chromatogr. A 2000, 880, 203-232. [CrossRef]

23. Wu, Q.; Wang, M.; Simon, J.E. Determination of isoflavones in red clover and related species by high-performance liquid chromatography combined with ultraviolet and mass spectrometric detection. J. Chromatogr. A 2003, 1016, 195-209. [CrossRef] [PubMed]

24. Vallejo, F.; Tomás-Barberán, F.A.; Ferreres, F. Characterisation of flavonols in broccoli (Brassica oleracea L. var. italica) by liquid chromatography-UV diode-array detection-electrospray ionisation mass spectrometry. J. Chromatogr. A 2004, 1054, 181-193. [CrossRef] [PubMed]

25. Albach, D.C.; Graye, R.J.; Kite, G.C.; Jensen, S.R. Veronica: Acylated flavone glycosides as chemosystematic markers. Biochem. Syst. Ecol 2005, 33, 1167-1177. [CrossRef]

26. Horvath, C.R.; Martos, P.A.; Saxena, P.K. Identification and quantification of eight flavones in root and shoot tissues of the medicinal plant Huang-Qin (Scutellaria baicalensis Georgi) using high-performance liquid chromatography with diode array and mass spectrometric detection. J. Chromatogr. A 2005, 1062, 199-207. [CrossRef] [PubMed]

27. Kazuno, S.; Yanagida, M.; Shindo, N.; Murayama, K. Mass spectrometric identification and quantification of glycosyl flavonoids, including dihydrochalcones with neutral loss scan mode. Anal. Biochem. 2005, 347, 182-192. [CrossRef] [PubMed]

28. Wang, D.; Wang, J.; Huang, X.; Tu, Y.; Ni, K. Identification of polymethoxylated flavones from green tangerine peel (Pericarpium Citri Reticulatae Viride) by chromatographic and spectroscopic techniques. J. Pharm. Biomed. Anal. 2007, 44, 63-69. [CrossRef] [PubMed]

Sample Availability: Samples of the compounds chrysophanol, emodin, aloe-emodin, rhein, physcion, emodin 8-O- $\beta$-D-glucoside, sennoside A, sennoside B, sennoside C, aloin, piceid, hesperidin, resveratrol, luteolin, nobiletin, sinensetin, tangeretin, vitexin, quercetin and hyperoside are available from the authors.

(C) 2016 by the authors; licensee MDPI, Basel, Switzerland. This article is an open access article distributed under the terms and conditions of the Creative Commons Attribution (CC-BY) license (http://creativecommons.org/licenses/by/4.0/). 